\title{
Тенденции использования венгерской орфографии в русинском языке
}

\author{
МАРИАННА ЛЯВИНЕЦ-УГРИН \\ ELTE BTK Szláv és Balti Filológiai Intézet, H-1088 Budapest, Múzeum krt. 4/D. \\ LyAvinECZ-Ugrin Marianna, Institute of Slavonic and Baltic Philology, Eötvös Loránd University \\ E-mail: mariann.ljavinecz@gmail.com
}

(Received: 31 January 2018; accepted: 16 March 2018)

\begin{abstract}
One characteristic feature of the vocabulary of Rusyn language which makes it different from the vocabulary of other East Slavic languages is the presence of Hungarian loanwords in it. From the middle of the 19th to the early 20th century, certain Rusyn authors wrote their Rusyn works using the Latin alphabet based on the Hungarian orthography. The paper is devoted to this phenomenon which remained almost unnoticed by the researchers.
\end{abstract}

Keywords: language contacts, Rusyn language, Rusyn literature, Hungarian orthography

Данная статья занимается исследованием истории русинских памятников письменности, созданных на основе венгерской орфографии. Самобытность их заключается в том, что они появились в разное время. В ходе работы нами были обнаружены русинские тексты или образцы текстов литературы (церковные книги, молитвенники, азбуки, грамматики и т. д.), делового стиля и жанра бытовой письменности с употреблением венгерского правописания. Хронологическое разнообразие таких письменных текстов позволяет нам предположить, что в истории русинского языка можно определить несколько этапов попытки перейти с кириллического правописания на латиницу, точнее - использовать венгерскую орфографию при написании русинских текстов.

Известно, что характерной чертой, отличающей лексику русинского языка от лексики других восточнославянских языков, является наличие в ее составе большого количества венгеризмов. Однако наше исследовательское внимание сфокусировалось на тенденции использования венгерской орфографии, которая не раз пыталась пустить свои ростки в русинском языке, оставаясь при этом малоизученной в кругу специалистов. На наш взгляд, каждый текст заслуживает отдельного внимания. Поэтому мы стремились в первую очередь провести не анализ текстов, а собрать появившиеся в различных научных работах уже существующие образцы и открыть для научной среды новые тексты с примерами рассматриваемого явления. В ходе исследований нам удалось найти несколько вовсе не изученных памятников русинской письменности, а также мы обнаружили упоминание о существовании ряда других текстов, о местонахождении которых пока неизвестно. 
На первоначальном этапе тенденция использования венгерского правописания в русинских текстах проявляется в официальных документах. Самые ранние зафиксированные сведения об употреблении венгерской орфографии в русинских памятниках письменности датированы 70-ми годами XVIII века. Речь идет о документах урбариальной ${ }^{1}$ реформы императрицы Марии Терезии. Это время правления первого просветителя русинского народа, епископа А. Бачинского. Урбариальные материалы широко представлены в работах А. Петрова, Л. Дэже, И. Удвари и др. Среди дошедших до нас документов находятся составленные на русинском языке записи комитатов Берег, Угоча и Марамарош (УдвАРі 1999: 13). Ввиду разных причин, на которых мы подробно не будем останавливаться, материалы были записаны венгерским правописанием того времени. Отметим лишь то, что конскрипторами могли быть венгры или словаки, которые хорошо владели венгерским языком. Вероятно, они прибегали к использованию латиницы, точнее - к венгерскому правописанию, потому что они не умели правильно или вовсе писать кириллицей (ДэжЕ 1996: 256). Как правило, урбариальная запись состояла из присяги, 9 вопросов, затем следовала самая существенная часть документа - ответы крестьян на вопросы (ДэжЕ 1996: 249). В качестве примера приведем варианты одного и того же вопроса: «Есть ли в данный момент урбар в деревне? Если да, то с какого времени?».

Czi je Teper Urbaria u szüm szelyi? Kegy Je, Je jaka toto i ot kotoroho csaszu uneszenna Je? (ДэжЕ 1996: 270, Дуличенко 2008: 69)

Czi maje szeje szelo Urbariu, koli maje? Jaka je, i ot kotoroho csaszu pocsalosza? (ДэжЕ 1996: 286).

Czi maje szesze szelo teper Urbariu? Koli maje jakaja jeszt? I od kotroho csaszu pocsala sza? (ДэжЕ 1996: 305, Дуличенко 2008: 74)

Czi maje szesze szelo szim csaszom Urbariu a od jakoho csaszu? (Удварі 1999: 111)

Очевидно, что венгерское правописание урбариальных записей зачастую неоднородно. По всей вероятности, это связано со степенью грамотности конскрипторов, а также с разницей локальных диалектов русинского языка.

Хотя на сегодняшний момент у научного круга исследователей в наличии существуют данные только о памятниках русинской деловой письменности с венгерским правописанием XVIII века, можно предположить, что в это время использование венгерского правописания в русинских текстах могло практиковаться и в церковной литературе. Эту гипотезу можно выдвинуть на основании взаимной закономерности, так как в Трансильвании обнаружены два текста молитвы Отче наш на венгерском языке, зафиксиро-

\footnotetext{
${ }^{1}$ Урбар (лат. urbarium) - документ о регистрации земельных участков, определяющий те дани и повинности крестьян по отношению к помещику, которые основаны не на законе (как девятина или десятина), а на договоре, обычае или воле помещика (подробнее об этом см. ПЕТРОВ 1908: 5-25, ДЭЖЕ 1996: 247-248).
} 
ванных в XVII и XVIII веке кириллическим «правописанием». Эти два варианта молитвы найдены в кириллических румынских церковных текстах: ${ }^{2}$

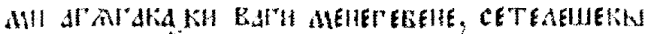

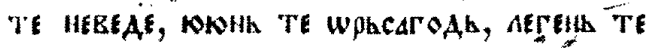

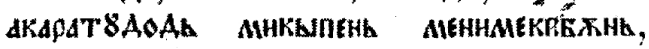

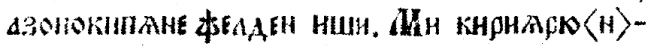

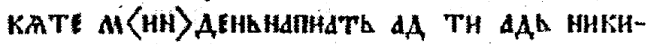

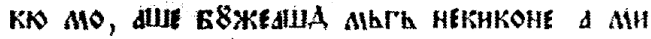

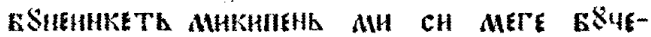

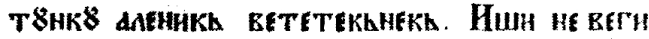

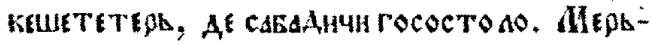
TETE TEAEAE a pOCar' \&TONOMh, \& AEWETh ME,WЕКК. IMUHL.

\section{Рисунок 1.}

Фрагмент из молитвы Отче наш на венгерском языке, зафиксированной кириллическим «правописанием» (XVII век) (MURVAI 1998: 1087)

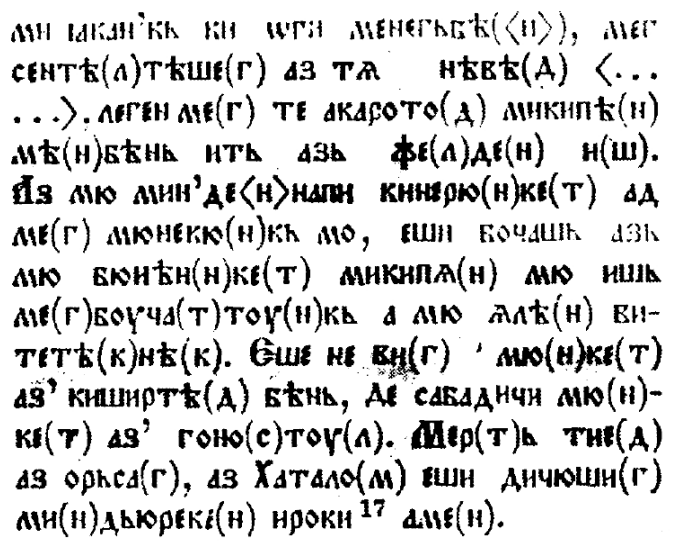

Рисунок 2.

Фрагмент из молитвы Отче наш на венгерском языке, зафиксированной кириллическим «правописанием» (XVIII век) (MURVAI 1998: 1090)

Первой книгой, которая была издана венгерской латиницей, был букварь (молитовник) А. Поповича Virnöj Anhel (1852) (Золтан 2011: 220). К сожалению, нам не удалось получить доступ к оригиналу этой книги, поэтому мы вынуждены опираться на сведения, изложенные в работе Е. Сабова, согласно

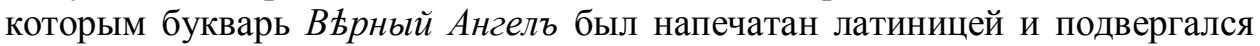
острой критике со стороны деятелей культуры (САБов 1893: 199). Об этом свидетельствуют и строки из статьи Е. Фенцика:

${ }^{2}$ Об истории найденных двух вариантов молитвы Отче наш на венгерском языке, зафиксированных кириллицей, см. MURVAI 1998: 1085-1092. 
Андрей Поповичъ благоденствующій еще и по нынъ и состоящій приходскимъ священникомъ въ Великой Копанъ (Veresmarth). Первый опытъ его письменной дђятельности состоялъ въ томъ, что онъ написалъ азбуку: »Virnöj Anhel«. Ocoбенность сей азбуки состояла въ томъ, что она была напечатана на одной сторонъ кирилликою, а на другой латиникою. Можно себъ представити, какая тьма носилась (впрочемъ она еще и днесь носится) на Угорской Руси, когда появился »Virnöj Anhel«, если даже и лучшіе сыны ея думали, что латиника годится для русскаго языка. Впрочемъ этотъ опытъ былъ внушенъ свыше и остался, къ счастью, безъ всякихъ посльдствій (ФЕНцик 1892: 197).

Интригующим остается вопрос о том, что побудило А. Поповича или кто мог внушить ему «сверху» создать книгу с параллельными текстами, ведь Virnöj Anhel увидел свет при правлении епископа Василия Поповича (18371864), сторонника русских традиций (НЕдзЕльский 1930: 129). В названии книги видны некоторые орфографические особенности принципа написания текста, например: $i$ служит для обозначения $b$, звук $b$ передается венгерской $\ddot{o}$, а 2 как $h$.

Небезынтересным может быть и следующий образец середины XIX века. Этот пример был замечен нами в книге об истории города Ужгород венгерского писателя и историографа К. Месароша. Курьезность его заключается в том, что кириллическую надпись на фасаде храма Крестовоздвиженского кафедрального греко-католического собора в Ужгороде автор книги проиллюстрировал венгерским правописанием, по всей вероятности - с целью облегчения прочтения текста. Описывая, как выглядел собор в то время, К. Месарош отмечает, что на фасаде под латиноязычным текстом с двух сторон на стенах колонны была надпись на «русском» и венгерском языках. «Русскоязычную» стихиру он приводит следующим образом:

\author{
Krest $^{3}$ Chranitely vozej uszelennyi \\ Kraszova ${ }^{4}$ czerkvam \\ Kreszt Czarem derzsava \\ Kreszt virnim utverzsdenije \\ Kreszt Anhelom szlava \\ Kreszt bibzom ${ }^{5}$ gazva $^{6}$
}

(MÉSZÁROs 1861: 65)

Несомненно, в приведенном примере много ошибок, и особенно опечаток. Поскольку книга была издана в Будапеште, они могли возникнуть и в процессе набора текста в типографии. Но, несмотря на это, приведенная запись может послужить примером одного из вариантов принципа написания русинского текста венгерским правописанием.

${ }^{3}$ Должно быть: kreszt, т. е. крест.

${ }^{4}$ Должно быть: kraszota, т. е. красота.

5 Должно быть: biszom, т. е. бъсом.

6 Должно быть: jazva, т. е. язва. 
В ходе исследований мы попытались разыскать литературные русинские тексты с венгерским правописанием середины XIX века, но наши поиски не увенчались успехом. Однако в грамматике Ю. Рамача мы обнаружили образцы текстов сремско-бачванских русинов середины и конца XIX века. Первый - это отрывок из кулинарного рецепта одной жительницы поселка Руски Керестур:

Pol kili muki, fertaly maszci... poldeczi smetanki, czeszto rizczelycz napoli, pomaszczic..., 10 mandulyi uvaricz u mlyeku (РАмАч 2001: 552). ${ }^{7}$

Следующий образец является отрывком из хроники поселения Руски Керестур (конец XIX века):

1746. Keresztur naszelyeli; 18[..] velyka voda bula, velyki dizsdzsi padali; $18[.$.$] ma-$ gyarska buna bula; 18[..] velyka voda bula, begely kopali (РАмАч 2001: 552-553). ${ }^{8}$

Вышеизложенные примеры позволяют нам заключить, что в середине XIX века использование венгерского правописания практиковалось среди русинов разных регионов Венгерского королевства, в различных жанрах письменности: церковной, деловой, а также в быту.

К концу XIX века использование венгерского правописания начинает тенденциозно проникать в русинский язык. В 1873 году министерством религии и народного просвещения Венгрии была предпринята попытка введения так называемого абеиадл $a,{ }^{9}$ но после проверки Мукачевской учебной консистории 15 января 1874 года она была отклонена (Листокъ 1890: 82). Однако спустя более чем 40 лет после выхода в свет книги А. Поповича Virnöj Anhel стремление использовать венгерское правописание в русинской письменности было повторено вновь. Одним из приверженцев этой концепции был о. И. Фестори, автор брошюры Zsivot Sz. Otca Nikólaja Mir-Likijszkich Csudotvorca. Hreko-katholicseskáho obrjáda vyrnyikam porucsaet Joszif Fesztóry, paroch vojcsickij, 1894 (Листокъ 1894: 218-219, НедзЕльский 1932: 241). Он предложил «основать» русинский литературный язык на основе марамарошского диалекта с венгерским правописанием. Несмотря на то, что нам не удалось отыскать оригинал текста, все же мы имеем некоторые сведения о принципе написания этой книжки. Дебаты по поводу данной языковой концепции бурно обсуждались писателями-русофилами на страницах духовно-литературного журнала Листокъ (1890-1895). Видный русинский писатель-русофил Е. Фенцик в одной из критических статей, затрагивающей правописание

\footnotetext{
7 'Полкилограмма муки, четверть жира... 50 грамм сметаны, тесто разделить пополам, помазать..., 10 миндалей отварить в молоке'.

8 ‘'1746 Керестур заселили; 18[..] было наводнение, шли большие дожди; 18 [..] шло Венгерское восстание; 18 [..] было наводнение, канал реки Бега (Бегей) копали'.

${ }^{9}$ В отличие от использовавшегося в Галиции в XVII-XIX вв. названия польского латинского абецадло, в русинском языке под термином абецадло подразумевается исключительно венгерская азбука.
} 
брошюры И. Фестори, выражая свое негодование по поводу этого издания «съ небывалымъ до сихъ поръ словацко-русскимъ нарьчіемъ, съ латинскими буквами, и съ неслыханнымъ до сихъ поръ въ мірђ мадьярскимъ правописаніемъ», подчеркивает грамматическую непоследовательность книжки и приводит несколько примеров:

...3вукъ $a$ пишется въ ней гдъ-то съ акцентомъ $a ́$, а индъ безъ акцента $a$; буква $b$ передается то буквою $y$, то буквою $i$ (и mysztyi стр. 4); употребляются такія слова какъ: ujecz, pozorlivo (это слово означаетъ постыдно), sziszál, zochábil и проч., которыхъ значеніе шатко, или русскому народу совсьмъ неизвъстно. Вообще вся брошюра дълаетъ такое впечатльніе, что это незрьлый и необдуманный трудъ злобнаго самоучки, который дорожитъ лишь своею фикса-идеею, а все то что дълалось до сихъ поръ на поприщђ науки, всь труды общепризнанныхъ ученыхъ оставляетъ безъ вниманія иль презираетъ (Листокъ 1894: 219).

В начале XX в. тенденция использования венгерской орфографии в русинских текстах начала интенсивно проявлять себя не только в церковной литературе, но и в общеобразовательных учебниках. В первую очередь это было связано с нарастанием процесса мадяризации русинского населения в Венгрии. На страницах венгерской прессы того времени появилась статья, сообщающая о том, что 9 августа 1915 года епископы ужгородской (Антоний Папп), пряшевской (Стефан Новак) и гайдудорогской (Иштван Миклоши) епархий собрали консилиум в Будапеште, на котором был обсужден вопрос об изменении правописания церковных книг. Согласно информации газеты Pesti Hirlap, венгерское правительство выделило 1500000 корон на издание церковных греко-католических книг. Епископам предстояло принять кардинальное решение - продолжать издавать книги на русском, то есть использовать кириллическое правописание, или же печатать их венгерскими буквами согласно венгерскому произношению (A rutének 1915: 6). На самом деле за вопросом правописания скрывалась проблема самосохранения русинов. Причиной возникновения проблемы были сложившиеся во время Первой мировой войны неблагоприятные обстоятельства для коренного русского (русинского) населения в Венгрии, где к тому времени даже кириллица считалась «смертельным врагом» (A rutének 1915: 6). В нацеленной против кириллицы (и всего, что русское) статье газеты Pesti Hirlap сообщается и о том, что русины уже давно пользуются венгерским правописанием, поэтому им переход на латиницу не составил бы проблему. В подтверждение этому, автор статьи указывает, что солдаты и даже эмигранты, поселившиеся в Америке, присылают письма домой на русинском языке венгерскими буквами. Также упоминается и о том, что в Ужгороде для учащихся сельских школ уже годами издаются русинские учебники с венгерским правописанием.

Переход на латиницу с венгерской орфографией совершался централизованно. Уже в ноябре 1915 года на полосах венгерской газеты Az est в статье Арпада Пастора был обнародован приказ пряшевского епископа С. Новака об использовании в начальных школах исключительно только таких 
учебников, которые написаны венгерским правописанием. В приказе также указан обязательный учебник: Rutén $A B C$ és olvasókönyv. A magyarországi rutén anyanyelv tanitásához egyházi szláv nyelvi olvasmányokkal [Русинская азбука и читанка с церковнославянскими текстами для обучения материнскому языку венгерских русинов] (Dr. Szemán István - Др. И. Семан) (PÁszToR 1915: 6). ${ }^{10}$ Однако было бы ошибочным считать, что эти книги издавались чисто венгерской орфографией. Это явствует из русинской азбуки А. Волошина, где подается алфавит расширенной латиницы своеобразного венгерского образца (Volosin 1916: 62). ${ }^{11}$

\section{AZBUKA.}

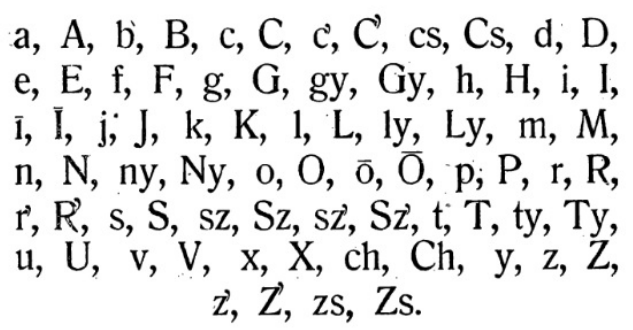

Рисунок 3.

Вариант венгерского алфавита из книги А. Волошина Azbuka uhro-rusz'koho jazöka (VoLosin 1916: 62)

Среди многих отклонений от традиционной венгерской азбуки мы отметим лишь следующие: используется $\ddot{i}$, отсутствуют долгие гласные $a ́, \dot{e}, \dot{o}, \dot{u}$,

${ }^{10}$ В ходе исследования мы обнаружили ряд учебников и церковных книг, которые распространялись в то время по епархиям. Часть из них нам известна из списка изданий издательства Унио (Volosin 1916: 111, Volosin 1917: 186). Перечислим лишь те, о которых однозначно можно определить по названию или подзаголовку, что они написаны венгерской орфографией. Некоторые из них носят лишь венгерское название. Это малый, средний и большой катехизисы некоего др. Микиты [Dr. Mikita], азбука и книга для чтения, а также малая библия A. Волошина [Volosin Ágoston]. Также здесь числятся книги: Anhel Hoszpodeny И. Семана [Szemán István], Chlyib Dusevnöj А. Карцуба [Karczub Endre], Velikij Zbornik П. Гебея и Й. Малинича [Gebé Péter, Malinics József] и Szerednij Zbornik А. Карцуба в соавторстве с И. Фленько [Karczub Endre, Flenykó János]. Немалое количество таких книг мы обнаружили в частной коллекции канадского ученого П. Р. Магочи Carpatho-Ruthenica Library, которая доступна в интернете на сайте https://archive.org/details/carpathoruthenica. Среди них: Szerednya biblia dlya narodnöch i nizsich szerednich skol (Ungvár, 1917) А. Волошина [Avgusztin Volosin], Zsizny pr. Gyivö Bohorodicö vo pisznech szlozsena vo cseszty obraza bozsoj materi na hori Lucinszkoj (Prasev, 1917) А. Шаламона [Adalbert Salamon] и Velikij Zbornik blahopotrebnöch cerkovnöch csinov $i$ szluzsb is csaszoszlova, oktoichta, triodej, trefolohiona, minei obscsija i litirikona (Po Szborniku, szosztavlennomu o. Petrom Gebé i Joszifom Malinics perepisav i dopolniv o. A. Volosin) (Ungvár, 1917). На сайте Русинская библиотека (http://rusyns-library.org/rusinskaya-literatura) доступно первое издание азбуки и книги для чтения А. Волошина.

${ }^{11}$ Другой вариант латинической алфавитной системы венгерского типа см. Дуличенко 2008: 844 . 
а также нет краткого и долгого гласного переднего ряда $\ddot{u}, \ddot{u}$ и т. д. Кроме этого подается лишь краткий гласный $\ddot{o}$, который в русинском языке, можно сказать, традиционно использовался для передачи звука bl. Например:

Kazsdöj por'adocsnöj gazda maje zahorodu (VoLOSIN 1916: 80).

Csudesza vo pustöni i desz'aty Bozsiich zapovidej (Volosin 1917: 41).

Bez laszki Bozsoj nics dobroho szgyilati ne mohli bö’szme (Volosin 1917: 41).

Velicsajem Tya, preszvjataja Gyivo... (GEBÉ-MALINICs 1917: 144).

Szkorb ï bolyizny obritoch, ï ïmja Hoszpodne prïzvach (GEBÉ-MALINICS 1917: 384).

В определенных случаях наблюдается неустойчивость выбора написания некоторых слов, которое может отражать и колебание в произношении. Например, в случае слова что:

Csto voszkresz z mertvöch tvoj Szön Marija (SALAmon 1917: 11).

Sto lyubov nasa lem vönajti mozse (SALAMON 1917: 16).

Наиболее поздний пример, о котором нам известно, это изданный в Будапеште в 1928 году текст Миссионерских советов (Дуличенко 2008: 292293). Он является свидетельством того, что латинизация русинского письма продолжалась и после распада Австро-Венгрии. Самобытность правописания этого образца заключается в употреблении долгого гласного $a ́$. Употребление этой буквы может объясняться тем, что простое $a$ ассоциировалось с лабиализованным венгерским $о$ [IPA: D].

Zá hrich Hoszpodj peklom káráje cseloviká (Дуличенко 2008: 293).

Jeszli precsisztu Djivu právdivo budes csesztováti, oszvobodisszjá ot tyáskáho hrichá i ot sztroháho szudá (Дуличенко 2008: 293).

Приведенный пример наталкивает нас на мысль о возможности существования различных типов венгерского правописания русинских текстов.

Несомненно, применение венгерской орфографии было тесно связано с постоянными контактами русинов с венграми, а также обусловлено рядом исторических и политических причин и обстоятельств. Латиница венгерского образца официально использовалась для передачи восточнославянской и церковнославянской речи и служила для издания собственно религиозной и учебной литературы. Как показало наше исследование, в культурно-языковой истории русинской письменности, начиная с конца XVIII века до 30-х годов XX века, эта тенденция не раз повторялась и в определенное время являлась даже общей тенденцией для русинов, проживающих в Венгерском королевстве. Использование венгерского правописания, с одной стороны, могло облегчить процесс образования, в том числе изучения родного языка среди простого русинского населения, а с другой стороны выполняло функцию ассимиляции русинов. 


\section{Литература}

ДуЛИЧЕнкО 2008 = ДуличЕнкО А. Письменность и литературные языки Карпатской $P y c u(X V-X X$ вв.). Ужгород, 2008.

ДэжЕ 1996 = ДэЖЕ Л. Деловая письменность русинов в XVII-XVIII веках. Словарь, анализ, тексты. Nyíregyháza, 1996.

ЗолтАн 2011 = ЗолтАН А. Латино-суrillica (кирилично-латинські графічні гібріди на плакатах і вивісках Львова). Hungaro-Ruthenica V. Szeged, 2011. 219-222.

Листокъ = Листокъ. Духовно-литературный журналь. Унгваръ, 1890-1895.

НЕДЗЕЛЬСКИй 1932 = НЕДЗЕЛЬСКИй Е. Л. Очеркъ карпаторусской литературы. Ужгородъ, 1932.

ПетРов 1908 = ПетРовъ А. Матеріалы для исторіи Угорской Руси. Вып. 5. Первый печатный памятникъ угорскаго наръчія. Урбанъ и иные связанные съ крестьянской Маріи Терезы реформой документы. Санкть-Петербургъ, 1908.

РАМАЧ 2001 = РАМАЧ Ю. Грамматика руского язика. Београд, 2001.

САБОВ 1893 = САБОВ Е. Христоматія церковно-славянскихъ и угро-русскихъ литературныхъ памятниковъ. Унгваръ, 1893.

УдВАРі 1999 = УдВАРі І. Русинські жерела урбанської реформы Марії Теризї. Nуі́regyháza, 1999.

ФЕНЦИК 1892 = ФЕнцик Е. Очеркъ угро-русской письменности. Листокъ. Духовнолитературный журналь. Унгварь, 1892. 196-197.

A rutének 1915 = A rutének és a magyar betűk. Pesti Hírlap, 1915. augusztus 9. 6.

GeBÉ-Malinics 1917 = GeBÉ Péter, MaLinics József: Velikij szbornïk blahopotrebnöch cerkovnöch csinov i szluzsb iz csaszoszlova, oktö̈chta, triodej, trefolohiona, mïneï obscsija i liturgikona. Ungvár, 1917.

MÉSZÁRos 1861 = MÉSZÁRos Károly: Ungvár története, a legrégibb időktől máig. Pest, 1861.

MurVAI 1998 = Murvai Olga: Két cirill betüs magyar nyelvü Miatyánk Erdélyben. In: A magyar müvelödés és a kereszténység. A IV. Nemzetközi Hungarológiai Kongresszus elöadásai. Budapest-Szeged, 1998. 1085-1092.

PÁszTOR 1915 = PÁsZTOR Árpád: Az első magyar fonetikájú rutén ABC és olvasókönyv. Az est, 1915. november 18. 6.

SALAMON 1917 = SALAMON Adalbert: Zsizny pr. Gyivö Bohorodicö vo pisznech szlozsena vo cseszty obraza bozsoj materi na hori Lucinszkoj. Prasev, 1917.

Volosin 1916 = Volosin Ágoston: Rutén ÁBC és olvasókönyv. / Azbuka uhro-rusz'koho jazöka. Ungvár, 1916.

VolOSIN 1917 = Volosin Avgusztin: Szerednya biblia dlya narodnöch i nizsich szerednich skol. Ungvár, 1917. 